\title{
Innovation through Internationalization: A Case Study Analysis of Indian Firms
}

Hrishiraj Sugre*

Department of Economics, Ministry of Information and Broadcasting, New Delhi, India

\begin{abstract}
This project is an inductive research project aiming to explore new and common innovative strategies of firms from India to internationalize and the challenges faced by Indian companies while going international in form of poor infrastructure, corruption and other aspects which most of the emerging nations have. In this paper strategies of Indian MNCs and companies in entering and competing in global market are studied, in context to, knowledge sourcing, production, technological innovations, brand image building strategies and challenges faced while doing so. Comparative study of the strategies by companies from similar industries is performed to explore better strategies.
\end{abstract}

Keywords: Strategy; Innovation; Comparison; India; Industry; Finance; Corruption; Economy

\section{Introduction}

\section{Background}

Lately, there has been substantial increase in Multinational Companies (MNCs) from the developing and less developed countries, especially BRIC nations. "No power on earth can stop an idea whose time has come." Said then Indian finance minister Manmohan Singh while presenting union budget on 24 July 1991 [1]. Which was in context to the liberalization of Indian economy. This allowed Indian economy to open for the world. As the foreign players entered the Indian market, competitiveness increased thus giving rise to few Indian companies to develop their products according the world standards and go international. Success of these companies is vital for the nation's economic health. Thus, PM Narendra Modi is also focusing on the policies to help Indian firms to grow in international markets. But not many of the Indian firms could make it big in global market due to, lack of world class infrastructure, complicated government policies and corruption. The paper also studies whether these aspects of a developing nation affect the brand image of the companies which originate from there. Usually, products from developing nations are considered inferior to those from developed nations, this paper will also discuss about this issue of 'country of origin effect'. Therefore, strategies used by Indian firms to go global are mainly centered towards similar economies. This is because firms from less-developed countries (like India) possess certain advantage in entering similar markets due to years of operation in home countries where both markets and institutions were underdeveloped [2]. The Indian pharmaceutical industry got advantage in international markets mainly by producing generic medicine which are significantly cheaper alternatives to branded drugs with similar active ingredients (sometimes excluding the inactive ingredients). While, reverse engineering and a growing domestic economy, helped Indian companies from technological industries to innovate and produce world standard products. The Indian mobile phone companies have come into existence in last decade and are even new for Indian market. But still they are growing internationally in-order to catch up to the competition posed by Chinese counterparts like Lenovo and Xiomi. A similar campaign was done by Karbonn earlier [3].

Three industries in India out of many which tasted success abroad are automobile industry, pharmaceutical industry and mobile phone industry. To understand the strategies adopted by Indian MNCs in entering and competing in global market, in this paper analysis of challenges and strategies of Indian companies is studied. In context to their innovative international strategies, knowledge sourcing strategies, production strategies, technological and brand awareness strategies. The paper not only focuses on the alliances or acquisitions made by Indian firms to go international but also the brand building strategies for international markets. The failed strategies and challenges faced by Indian companies are also discussed to gain more insight on their international operations. The companies which are mainly focused in this paper are Thermax an energy engineering company, Netsurf is a manufacturer of bio and herbal products for agriculture and health care, TATA Motors (TMs) and Mahindra and Mahindra (M\&M) leading Indian automobile companies, Dr. Reddy's (DRL) and Cipla leading Indian pharmaceutical companies, Micromax and Karbonn leading Indian smartphone companies.

\section{Researchquestions}

RQ1. What are the internationalization strategies adopted by Indian MNCs to source knowledge by different mechanisms in different countries?

RQ2. Which common strategies do Indian MNCs adopt to innovate through internationalization?

RQ3. Which unique strategies do Indian firms adopt to enter and compete in global market?

RQ4. What strategies are used by Indian firms for brand awareness and image building?

RQ5. Is there any pattern which firms from similar industries in India follow to internationalize?

*Corresponding author: Hrishiraj Sugre, Department of Economics, Ministry of Information and Broadcasting, New Delhi, India, Tel: 01908830001; E-mail: hrishirajsugre@gmail.com

Received November 18, 2017; Accepted December 26, 2017; Published January 02, 2018

Citation: Sugre H (2018) Innovation through Internationalization: A Case Study Analysis of Indian Firms. J Glob Econ 5: 276. doi: 10.4172/2375-4389.1000276

Copyright: () 2018 Sugre $\mathrm{H}$. This is an open-access article distributed under the terms of the Creative Commons Attribution License, which permits unrestricted use, distribution, and reproduction in any medium, provided the original author and source are credited. 
RQ6. What are the challenges faced by Indian companies in international market?

\section{Significance of the project}

This is an inductive research project which will explore different mechanisms of Indian firms to enter and compete in different markets will help in understanding the pattern of Indian Outward Foreign Direct Investment (OFDI). The paper will help in understanding challenges faced by a company from emerging nation. This project will be useful for potential firms from India to go global, it can also be useful for the firms on which this project is made to innovate and to compare their position or strategies with world leaders and competition to grow and develop. Knowing emerging economies face similar issues and have similar underdeveloped infrastructure, market and culture (to some extent), this project will also be useful for the potential firms of other emerging economies to plan their international journey. This project shall also contribute to the concerned government to frame the trade policies according the need of its firms. This will develop its domestic players and would encourage them to go global, resulting in positive effect on the balance of payment of the nation. Most importantly, this project will help in identifying new innovative strategies of internationalization by using combinations of different successful strategies followed earlier. For companies with similar business models this project can be helpful in avoiding mistakes or flaws in strategies of going international to sustain the global competition and gaining more market share. On the global level, all the MNCs would benefit from this project to identify innovative solutions for unique challenges. This project is also helpful for existing global market leaders to understand the pattern of growth of firms from emerging economies to curb their growth at the initial stage to maintain their market leadership. Finally, this study shall also contribute to providing data to students and universities.

\section{Existing Strategies of Indian Firms}

\section{Knowledge-sourcing and mode of entry strategies}

Mergers and acquisitions: Mergers and acquisitions is widely used strategy to enter in international market. However, it is very expensive and that is why it is not an option available to all the companies. In the automobile industry of India, Tata has decided to focus on a narrow base of 14-15 countries where market conditions are similar as India [4]. Tata motors acquired Jaguar and Land Rover to give the company a global image, to get latest and high end technology which could also be used in other Tata motors vehicles, to get into luxury and off road car market and to get strong global access. 'Tata Motors' acquisition will give the Indian auto major access to latest technology and help its wings to foreign geographies.' (ETC opinion, 2008). TATA Motors' revenue for the financial year 2016 was US $\$ 40$ billion. Since, TATA acquired JLR, JRL has been self-financing its operations and the revenue for 2016 was US\$22.2 Billion. Talking about the pharmaceutical industry of India, Cipla has said it is not "compelled" to go in for major M\&As, preferring instead a semi-inorganic route to expand its global footprint (ET Bureau, 2015). The acquires and the mergers are planned to be funded by internal accruals [5]. It acquired InvaGen Pharmaceuticals and Exelan Pharmaceuticals for $\$ 550 \mathrm{mn}$ to get significant foothold in the global market [5]. The plan to acquire InvaGen was to get more market share in US generic medicine market and to get access to the US Food and Drug Administration approved facilities. The step also helped Cipla to get a wider product portfolio, which would also mean getting a stronger supply chain management system of wholesalers and retailers to push down the products into global markets. While, InvaGen got Cipla access to the market and facilities, Exelan got them access to government markets as well as institutional clients too. They planned global expansion in three phases, which includes entering partnerships for the US and European market, and expanding the respiratory and injectable portfolio [6].

On the other hand, Dr. Reddy's Laboratories Ltd. (DRL) is a dominant global player which prefers inorganic growth in the global market even after facing losses by acquiring Betapharm from Russia. DRL chairman G V Prasad said the management was well on course to building the company as a dominant global pharmaceutical player with the inorganic growth and globalization being the driving theme [7]. DRL seems to significantly outclass Cipla in international market with the dominant and risk taking behavior of the company. Initially, DRL got into joint ventures with Russian and Middle Eastern companies to bulk export the products in less regulated markets to get focused on getting approval from drug regulators to enter US and European markets (Dr. Reddy's Laboratories, n.d.). Cipla is concentrating more on inhalers segment to get strong position in US and European markets as inhalers are the top sellers in both the markets [8]. While Cipla is focusing on inhalers for international markets, DRL is focusing on generic medicines to compete on price with global players. In 1997, Sun Pharma initiated their first foray into the lucrative US market with the acquisition of Caraco Pharmaceuticals, based in Detroit [9].

Thermax Pvt. Ltd. operates in 72 countries world-wide and approximately has around \$225 million worth exports annually [10]. It made successful international acquisitions to enter international markets. For example, Danstroker A/S to enter Europe and its German subsidiary Omnical Kessel at the cost of Euro $29.5 \mathrm{mn}$. Motherson Sumi Systems, the company came into existence as a joint venture between India's Samvardhana Motherson Group and Japan's Sumitomo Wiring Systems. The company is a leading automotive mirror and wiring harness manufacturer for passenger cars. After growing organically for many years and having presence in all important markets, the company acquired Visiocorp and Peguform to further expand its presence. It now has offices and manufacturing units in 24 international and 11 Indian locations. Mergers and acquisition is a very common tool amongst MNCs from emerging countries to source knowledge and the trend seems to be increasing every year. Figure 1 explains in detail.

Strategic alliances: Mahindra and Mahindra (M\&M) also initially started exporting its vehicles to countries like Yugoslavia, Indonesia and African countries which were like Indian market back then [11]. While M\&M were not as financially strong as Tata they could not acquire a globally known automobile brand. Therefore, instead of acquiring one big brand they entered in alliance with global players like SsangYong, Saab and Peugeot Citroen to get access to global market and latest technology [12]. M\&M's revenue for the year 2016 was US\$11 billion, On the other hand, Mahindra's strategy to get into alliance with SsangYong failed and in 2015 M7M had to face Rupees. 31.2 billion in losses due to SsangYong's poor performance in Russia and China. Which were M\&M's most important markets for international operations [13]. But the more successful strategic alliances of M\&M are with Mitsubishi and an Australian aircraft company. With the help of their strategic alliance with Mitsubishi Agri Machinery, M\&M designs and manufacture world standard tractors. And with the help of the Australian aircraft company M\&M manufactures Airvan 8 aircrafts. Cipla has strategic alliances with 


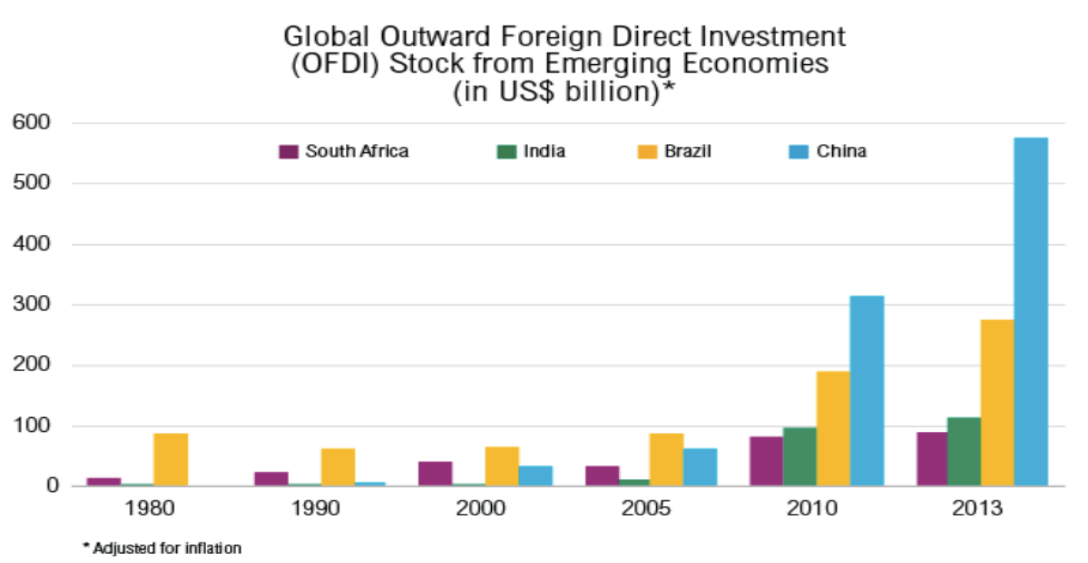

Figure 1: Global foreign development and emerging economies.

Drug Master Files (DMFs) and Abbreviated New Drug Associations (ANDAs) in the US to seek authority to sell drugs in various markets i.e. to obtain various certifications from various jurisdiction. Netsurf has recently got into JVs with undisclosed companies from south Korean, US and Sri Lankan companies for their international start and to source knowledge in international market. Karbonn mobiles currently have their markets and handset bundling (in subsidized countries) in 40 odd countries of Indian sub-continent, Middle east and some parts of Russia and Europe. In-order to finance their global expansion to 25 new countries across South East Asia, West Asia, Africa and Eastern Europe, the company is selling out $20 \%$ of its stake. According to Shashin Devsare, Executive Director of Karbonn, this will also strengthen their operation in existing countries [14]. On the other hand, Micromax is also operating in similar markets like Karbonn and has similar country targets but it is trying to raise its funds for global expansion via IPO [15]. The key difference between both the companies in terms of international aspirations is that Micromax is also looking to compete in Chinese market to reduce the heat it is facing by the Chinese rivals. On the technological side, Karbonn is getting into alliance with Microsoft to build Microsoft based Karbonn phones for the Russian market and Micromax is focusing on cloud storage as it invested in New York based MiMedia which is a Cloud Storage Provider [16]. In November 2016 Karbonn announced its collaboration with Cube26 which is an AI startup to add native applications on the device named REOS. These apps will filter spam messages, improve music player's access and add few features to the camera to make the new devices appealing to the customer [17].

In July 2015, Dr. Reddy's announced a strategic tie-up with USbased Purdue University to strengthen pharmaceutical R\&D, which the company said would accelerate innovative drug development [6]. In 2012, DRL had tied up with Merck Serono, a division of Merck KGaA based in Germany, to co-develop biosimilar molecules. As per the deal, DRL would lead the early product and phase I development; Merck Serono will take over manufacturing of the compounds and will lead phase III development. While, Venturing into the vaccines segment, Cipla, through its subsidiary Cipla Europe NV, has entered into an agreement to distribute Serum Institute of India Ltd.s (SII) pediatric vaccines in Europe. As per the agreement, Serum Institute of India, a Poonawalla group company and one of the leading manufacturers of vaccines in India, will develop and manufacture pediatric vaccines, while Cipla will seek European Medicines Agency approval and market the products in Europe. The vaccines will be manufactured in Serum's production facilities approved by WHO [18].

\section{Productionstrategies}

Being a MNC it is very important for the company to rope in the best available resources from around the globe to make the brand truly international and the products of the best quality possible. Tata motors group is a MNC which has around 6,600 touch points network globally [19]. Europe, especially Italy has always referred as the country for best designed cars and for world's best hyper-cars. Thus, to have such design and expertise Tata motors have design centers in in Italy and UK. Having said that Tata motors also has design centers in Africa, India, South Asia and South Korea. This strategy is to get the best expertise available in the world as well as to understand trends from every region. Following is the map for Tata Motors Group worldwide design and manufacturing centers (Figure 2).

Talking about M\&M, they also have their R\&D and production facility in Italy to gain the art of creating world's finest car design. M\&M's other design and production facilities are in India, China and Japan. These three facilities work in sync to design and produce tractors for global consumption. Therefore, in China and Japan M\&M has alliance to gain more expertise in the product designs for its tractors. Also, M\&M passion for electronic vehicles made them set up a design facility in 'Silicon Valley' USA to design and produce electronic scooter named Mahindra Genze Electronic Scooter in Michigan [20].

Pharmaceutical Industry is one of the industry which is mostly driven on intense and rigorous R\&D facilities. DRL has thus set up their R\&D facilities in Hyderabad (India), Princeton (USA), Basel (France), UK and USA [21]. All these facilities of DRL work together to innovate and develop new drugs for world consumption. Cipla has their R\&D centers in India, USA, UK, South Africa and Australia [22]. These R\&D centers are strategically located for better drug delivery and for reverse engineering. TATA's brand TITAN a watch and perfume brand launched a brand called SKINN which manufacture perfumes. Thus, to avail the best resources and expertise in the field of the same, SKINN's R\&D and Assembling plant was strategically placed in France [23]. 


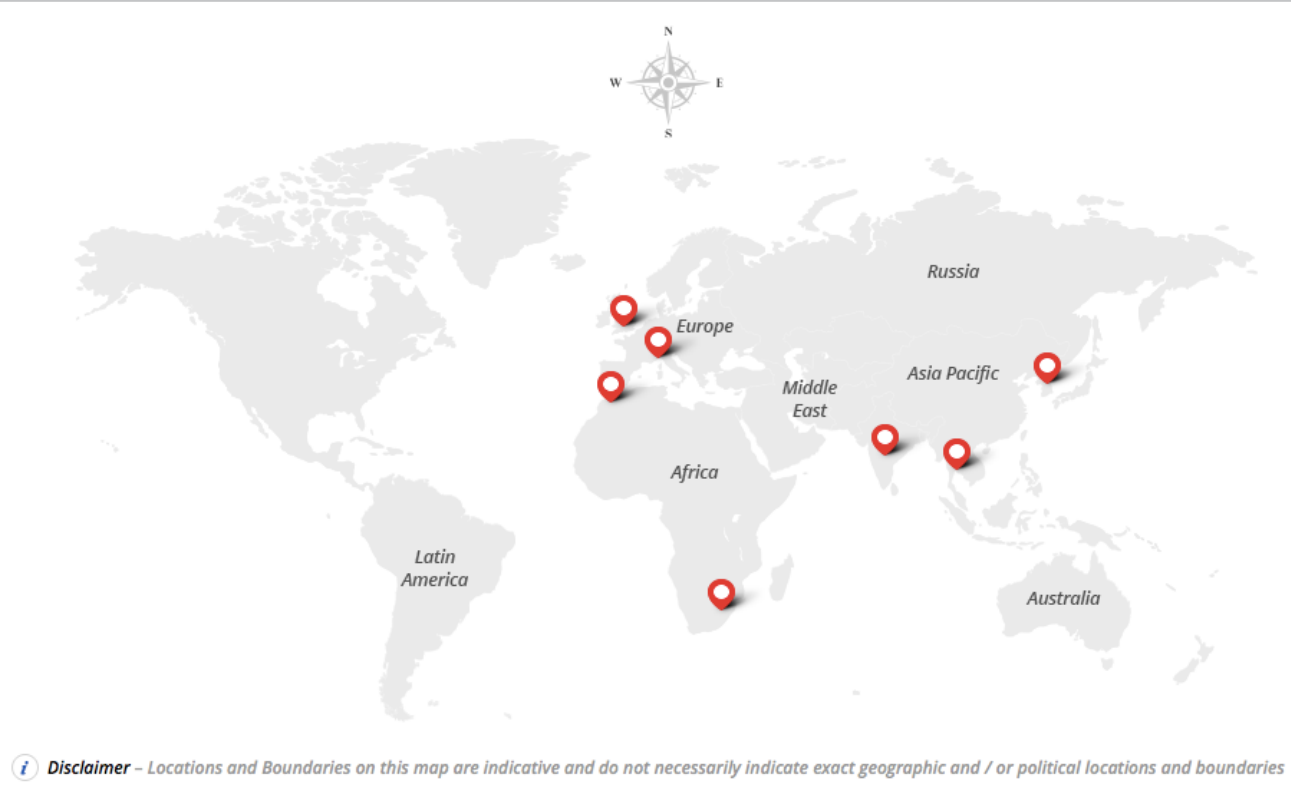

Figure 2: Tata motors group worldwide design and manufacturing centres.

\section{Brand image building strategies}

Global star as brand ambassador: A globally renowned star is appointed as brand ambassadors by the companies to make the company's brand image as a global company and to reduce the impact of country of origin effect. In February 2016 Geunter Butschek was appointed as CEO and MD of Tata Motors and it seems reducing brand dissonance is his priority [24]. Also, Tata hired Lionel Messi the world class football player to promote the brand.

In 2013 Micromax signed Hugh Jackman to give the brand a global appeal and to remove the country of origin effect from the brand. The link to the clip of the advertisement is attached in the Appendix. In a press release Shubhodip Pal, Chief Marketing Officer of Micromax said, "We are very excited to welcome Hugh Jackman in the Micromax family as he truly embodies the aspirational, reinventing and fearless persona of the brand Micromax. As we look to expand our footprint across the globe in various international markets, the association with the Hugh Jackman is an ideal partnership for us to connect with audiences as he is the leading name in the entertainment industry in the world" [25]. The company was trying to create Micromax's image as a fearless brand who would not fear to take on Chinese counterparts in China. However, in 2016 the company understood that only $10 \%$ of the domestic population of India can read and write English.

Other examples include, an attempt to close the gap to market leader Rajnigandha (pan masala company), Pan Bahar has roped in former James Bond star, Pierce Brosnan. A film featuring him has been conceptualised by DDB Mudra and went on air today, 7 October 2016 [26].

Hero MotoCorp the world's No. 1 two-wheeler manufacturer by volumes, has roped in Tiger Woods as its brand ambassador in a four-year deal pegged at Rs 200 crore, making it the most expensive celebrity endorsement yet for an Indian company [27]. This was done to approach the global image and associate Hero as a globally leading brand.
Local star as brand ambassador: As local stars are more appealing to local population than global stars, many companies appoint local stars as ambassadors for local markets. For example, to appeal the Australian market, M\&M roped in Matthew Hayden the famous Australian Batsman as their brand ambassador. Monty Betham famous rugby league and boxer from New Zealand for New Zealand's market. For south Indian market M\&M hired South Indian superstar Prabhas and Bollywood superstar Kareena Kapoor for Northern India.

Micromax, which lost its appeal in domestic market due to its aspirations in international markets hired famous Indian Comedian Kapil Sharma to promote Micromax's new feature of multiple languages. $\mathrm{AB}$ de Villiers, the South African all-rounder, was the recent sportsperson to ink an advertising deal with Chennai-based Madras Rubber Factory Limited. Former international cricketers Steve Waugh and Brian Lara too had tied up with the Indian tyre manufacturer to promote its flagship rubber and sporting equipment in the early 2000s [28]. This strategy was to promote the brand to the nations of each player signed.

Brand positioning: To revamp the positioning Tata is all set to launch a new brand named "TAMO" under which they will launch cars with latest feature and technology and their first car will be launched at the Geneva Motor Show this year [29] will position it as semi-sports car. Similarly, Mahindra's recent 3 years $120 \mathrm{Cr}$ rupees marketing plan was called 'RISE' which was focused to generate a global brand image of excellence and to promote their commercial vehicles like pickup trucks and tractors in global market [30]. M\&M also launched a T.V commercial which carries the tag line live young, live free' and the cars are shown to be rugged and strong to target the youth.

India's second-largest handset maker Micromax is stepping on the gas, revamping products with "connected devices and services" and expanding to more emerging markets as it aims to become one of the top five global players by 2020 [31]. Micromax launched 20 smart devices at one go recently: 15 smartphones, two LED TVs, two 
tablets and a smart watch. The company also announced its brand new corporate strategy, which it called Micromax 3.0, and released its newly designed logo [32].

Karbonn is positioning itself as a multi-tasking smartphone company by airing three short films, the campaign illustrates how youngsters, Karbonn Mobiles' target group, are incapable of physically doing two unrelated things at the same time [33].

Dr. Reddy's Laboratories, country's second largest pharmaceutical company by revenue, has undergone an image makeover signaling a shift in its focus from a research led strategy to one that is patient led [34]. This is to position the brand as innovation driven brand. Netsurf positions its health care brands 'naturamore' and 'herbs and more' as ayurvedic and herbal health care solutions. Surprisingly, all above products are also positioned to be relative cheaper option to the international competition and propose value for money over premium quality.

\section{Technological innovation strategies}

New innovative product/process: In the year 2009, Nano announced as the most affordable production car in the world, Tata aimed for a price of one lakh rupees, or ₹ 100,000 , which was approximately $\$ 2,000$ US at the time [35]. This was an innovation by Tata by designing a four doors car at the price of a two-wheeler scooter. Tata's Nano was composed out of several well-known technological solutions, such as the usage of plastic instead of metal, identical and modular components and is supplying a share of up to $40 \%$ of the car's components via internet auctions. All together these factors constituted a successful innovation strategy, which is worth to be imitated by more companies from other emerging countries [36]. After launching world's cheapest car, Tata innovated in manufacturing technologically at par with modern world semi-sports car TAMO Racemo. The car is loaded with smart features which even most of the best cars does not have. The car is powered by Microsoft software, intuitive human-machine interface, cloud computing and geographical analytics [37]. M\&M has been innovative from introducing India's first 5\% bio-diesel tractor to launching the Mahindra Shaan - India's first multi-utility tractor with which one can perform farming activities and can be used for transportation. M\&M innovated in the field of electric vehicles by introducing e2o an electric hatchback, Mahindra Genze Electric Scooter in US and Mahindra Blazo a full-size truck with electric batteries and smart features.

In 2016, they innovated with their product 'Nicotex' which is a Nicotine Replacement Therapy for quitting smoking. The Nicotex which was in form of a chewing gum they added new feature to it which was to cleanse teeth and remove mouth odor as well, which no other competitor is offering. To operate better in the global market Cipla outsourced its subsidiary Cipla Medpro's forecasting, inventory and replenishment planning to Tools Group. This step has helped Cipla to reduce their inventory levels dramatically and to lessen the burden of these processes, so that they could focus on other important activities of the business. We are already working on measures for increased compliance and efficiencies at our manufacturing plants and we are improving our quality culture," said Dr. Ranjana Pathak, global head of quality of Cipla on the sidelines of Indian Pharmaceutical Alliance event on $23{ }^{\text {rd }}$ February 2017. This is done mainly to improve drug quality for global consumption which will help the brand to be considered of top quality (Phadnis, Cadila, Cipla step up investments for improved drug quality, 2017).
DRL recently indigenously developed and filed two new drugs with the USFDA. The drugs are for dermatological and neurological ailments and DRL is the first Indian company to indigenously develop and file drugs at the USFDA. DRL's wants to get a sustainable cash flow for future by launching such difficult to make products. DRL also stated that 15 such new products are in their pipeline for future.

Micromax is also trying to diversify in products like television sets, air conditioners and laptops for better and wider portfolio in domestic and global market. Karbonn to answer the competition from Micromax also announced launching of LED TVs and all the TV sets will have an integrated Karbonn app on which the users will get 200 free movies. Thermax set up another headquarters in Britain, to look after European and American markets without facing infrastructural problems present in India.

Modification of existing product and reverse engineering: Tata Motors launched new 2.2 'VariCOR' diesel engine which has 16 valves and produces $120 \mathrm{PS}$ of power and $250 \mathrm{Nm}$ of torque. This VariCOR engine is fuel efficient as well as powerful than other Indian. 2.2 diesel engines (Tata Motors, n.d.). Similarly, Mahindra also launched mCRD engine for its tractors which is fuel efficient, powerful and more environment friendly.

Talking about the innovations in the products at Cipla, they are more into reverse engineering of the existing medication to create a new medication for much cheaper price. The drug Triomune by Cipla is just a \$ per day, a combination of three anti HIV drugs. Which earlier was offered by other brands for around $\$ 1000$ yearly. Similarly, they designed and launched new inhaler called 'Synchrobreathe' in 2015 at South Africa Thoracic Society (SATS) conference in Cape Town. This inhaler which they launched was the most user friendly as effective for patients with obstructive breathing disorders (ANI, 2015). This step gave them recognition in the global market of inhalers. Also, in this department of innovating the products DRL looks to surpass Cipla In contrast to Cipla's reverse engineering strategy DRL is adopting to incremental innovation strategy in which it is making new products using known molecules, which is less time consuming and cost efficient and has long term returns in the developed markets and for the emerging markets they are developing Biosimilar products which are generic medicines with organic compound. The result is $35 \%$ annual growth of the company in emerging economies. In a recent interview to McKinsey, Dr Reddy's co-chairman and CEO, G V Prasad, said the company's business model will undergo complete change in ten years. A large part of the company's revenue comes from generic medicine today, while in ten years much of it would come from innovative products. Cipla is focusing more on gaining market share as fast as they could and DRL is looking for long term benefits. Micromax and Karbonn also reverse engineer existing smartphones in the global market to come up with a cheaper alternative. For example, both the companies have touch screen phones like Samsung.

\section{Sourcing of raw materials}

Strategies of Indian companies relating to sourcing of raw material for global production are very similar despite of different industries. For example, Mahindra's one sourcing strategy which is aimed to reduce their supplier by dealing with one dealer for various components. This ultimately gives the vendor economies of scale and centralized purchasing system which cuts down the cost of production. Similarly, Tata Motors also try to provide their vendors economies of scale to cut down the production cost. However, Tata 
motors have joint ventures with Johnsons control Ltd. For seats, Knorr Bremse CV Systems for air brakes, Yazaki Autocomp for wiring harness, JBM Sangwoo for pressed components and Toyo radiators for radiator assemblies. Overall Tata has $30.56 \%$ stake in these JVs which gives Tata a fair amount of control over its raw materials. While, both Tata and Mahindra source the resources locally to keep the transportation cost low helping them in keeping the cost of production low which will then give them an edge over the competition in the global market.

Tata Motors' vendor rationalization program which provides economies of scale to its vendors and suppliers. Which in return helps the company in cost reduction and sustaining in the global market. On the other hand Mahindra and Mahindra have targeted to reduce their supplier base by $10 \%$ each year from 2014 to 2019 . The program is carried out to cut down the current 650 suppliers to over 450 which will help in cutting down the cost of procurement by 2 to $3 \%$, also resulting in a more efficient supply chain.

Due to PM Modi's Make in India campaign Micromax is planning to manufacture all its devices in India by 2018. Most of which are in China as of now. Chairman of Micromax Rahul Sharma said it would be beneficial to the company as labor in India is cheaper than China. $\mathrm{He}$ also said it is mainly due to increase in cost of labor and resources in China and increase in suppliers in India. Mr. Sharma stated earlier India lacked ecosystem which made the company to produce in China due to ample of suppliers and cheap labor but now the picture is changing and India is going to prove beneficial in future to the company. Karbonn mobiles' Sudhir Hasija told Economic Times that "By the end of June we will start assembling smartphones in our Noida Facility, which is being set up currently. The Bengaluru assembly will start production by July end," And bringing complete supply chain to India from China. It's a clear sign that both the companies are looking to cash on India's cheap labor and governments support to make in India to keep the production cost less. Another reason behind Micromax and Karbonn to manufacture their devices in India is that Government of India increased duty on components of mobiles and tables to India. This has made raw material expensive for both the companies thus it would be better for both to source raw material from Indian suppliers and to manufacture in India. While Indian Mobile phone manufacturers are being forced to manufacture in India by the Indian government, Indian pharmaceutical companies like DRL, Cipla, Sun, Ranbaxy are forced manufacture in US as the US government made it mandatory for Active Pharmaceutical Ingredients (APIs) to be manufactured locally and currently $80 \%$ of which is met by India and China. This has put Indian companies in a state where they can either produce APIs in the US or exit the market of supplying raw materials to the US. This helps us to witness the effect of government policies on the operations of a global company.

\section{Product selection strategies}

Other than using cars to enter global markets Tata is also focusing on light truck vehicles and other commercial vehicles, knowing less competition in the segment. In Ukraine Tata is the leading competitor in the GVW light truck segment. With the very similar nature even Mahindra is concentrating on tractors and other farming and commercial vehicles in the global market, Mahindra is also one of the market leaders in the global tractor industry. Recently they invested $700 \mathrm{cr}$ rupees in commercial vehicles for expanding globally (Mahindra Invests Rs. 700 Crore in Commercial Vehicles and Expands Dealership Network, n.d.). Both Tata and M\&M are cashing on in the segment where price premium vehicles are not preferred, as customers who buy commercial vehicle look for cheaper and reliable vehicles to lower the investment. While TATA focuses on hatchbacks and sedans in Latin America and Asian markets, M\&M focuses on SUVs and pick-up trucks. After understanding the demand for small electric cars in the UK, M\&M launched e2o for UK market and added extra safety features and better quality parts compared to Indian model. Charts to understand M\&M product selection strategies are attached in the Appendix. Karbonn sensed demand for Microsoft mobiles in Russia, thus it got into an alliance to build Microsoft based smartphones for Russian markets. As, discussed earlier Cipla introduced inhalers and cheaper HIV/AIDS medication in Africa by understanding the demand of the product.

\section{Failed strategies}

Talking about some failed Innovation strategies of these firms, Tata's biggest hope and biggest Global announcement of launching Tata Nano for one hundred thousand rupees in 2008 by Chairman Mr. Ratan Tata surprised the automobile market, Osamu Suzuki even doubted this move of Tata. As promised Tata delivered the car for promised price and was initially a hit but the sales significantly dropped due to increase in price of the variants, the 'cheap' tag associated with it and the car was not at all safe to drive due to inferior materials. Few Nanos were also pulled back due to fire reports. This affected Tata's brand image globally and it also affected the firm economically. Figure 3 helps us to understand the fall of Tata Nano from 2011 to 2014.

On February 32016 Tata launched their much awaited, hatchback at the Auto Expo in Noida and it was named 'Zica', this was the same car which Messi was supposed to promote. The global market did not take it well as the name was pronounced same as the deadly Zika virus which was caused by mosquitos. Tata after witnessing the heat renamed the name to 'Tiago' by conducting online campaign.

Mahindra's biggest failure was in their strategy of entering the US market with pickup truck "FORAY" in 2006 in which they signed a deal with US based distributor 'Global Vehicles' for distributing their pickup trucks in the US. In the year 2010, the deal fell apart and 5 dealers sued Mahindra in the US court accusing of not having any intention of doing business in the US and to con the deals for money and market information. This not only hurt Mahindra's brand image in the US but also globally. Figure 4 is the timeline of M\&M in the US.

Later in 2011 the company got certificate from the US Environmental Protection Agency stating the transmission of the vehicle was rated at $19 / \mathrm{mpg}$ than the over claimed $30 / \mathrm{mpg}$. This not only has affected plans of the company to enter the US market again but also credibility of the company with the foreign dealers

Recently, lack of execution hit DRL and which directly benefitted Cipla and another pharmaceutical company Torrent. The event was when DRL delayed in the launch of generic version of the drug Nexium which is a heartburn pill, thus Torrent got approval of selling the same in November 2015 and Cipla got benefitted as they are the suppliers of the ingredients to other company called Teva which is also licensed to sell the same drug. It was a huge loss to DRL as the Nexium's sell (branded generic) was calculated to $\$ 5.2$ billion by just June 2015.

\section{Challenges Faced By Indian Firms}

\section{Ease of doing business in India}

In the ecosystem of international market, governments and 
Citation: Sugre H (2018) Innovation through Internationalization: A Case Study Analysis of Indian Firms. J Glob Econ 5: 276. doi: 10.4172/23754389.1000276

Page 7 of 15

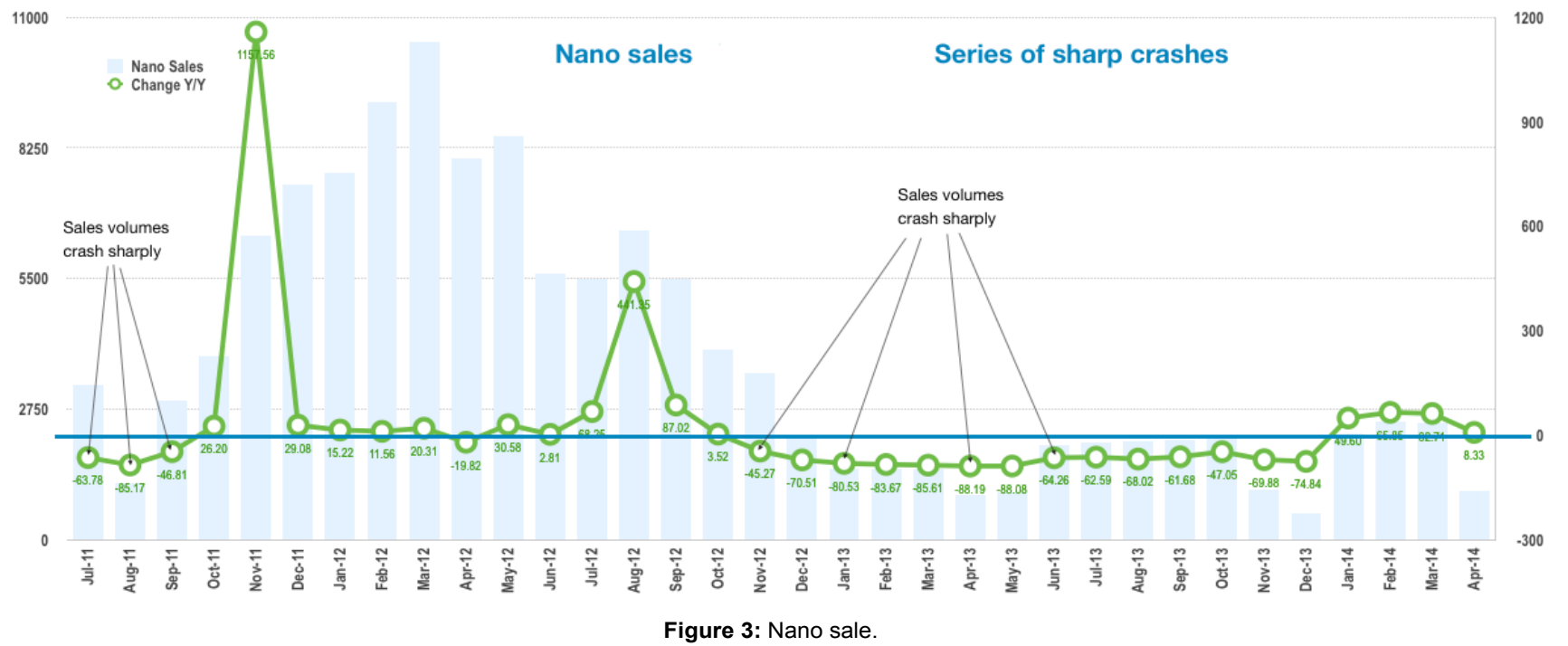

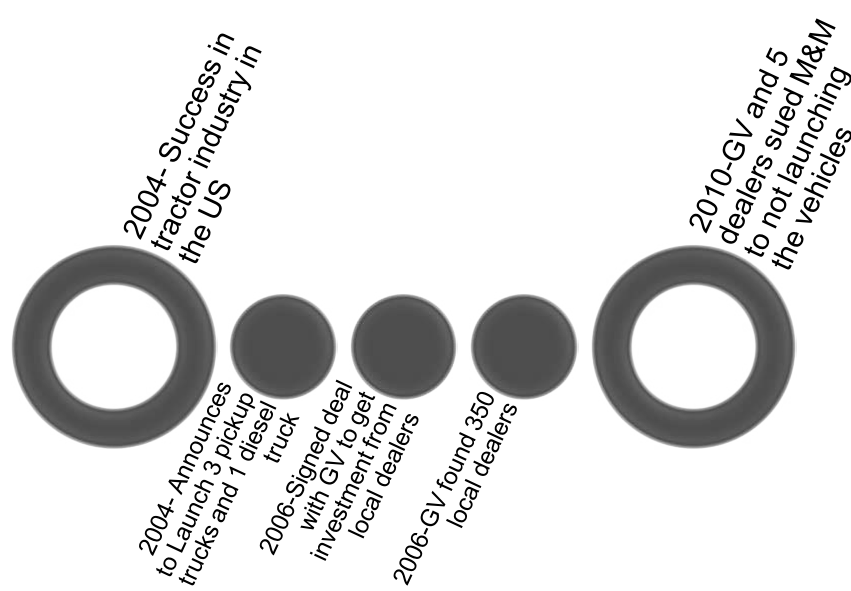

Figure 4: Timeline of M\&M in the US.

MNCs must work together to benefit each other. In India, businesses especially MNCs face tremendous problems like, poor infrastructure and time consuming government procedures. Story of India's relative lack of success (compared to its Southeast and East Asian comparator countries) is really about the failure of policymakers to enable India's smaller entrepreneurs to benefit from global opportunities. India's bigger and even some medium sized business houses have always found a way to manage around high transaction costs and trade facilitation issues, and they have always had a global footprint of sorts. The rapid expansion of that footprint in recent years only highlights the fact that Indian big business is still much more able, given its economic muscle and better political networking, to get around the system. But the MSMEs - the small start-ups, the smaller- town industrial units - are being stifled by this combination of high trade and entrepreneurial transaction costs, preventing such entrepreneurs from integrating into global production and distribution networks. When the business environment is not favourable for the businesses, local businesses find it difficult to focus on the operations and to gain more market share. Thus, reducing their chances of competing in global market. Complex regulations in India make it very difficult to commission a new business. Therefore, it is essential to have business

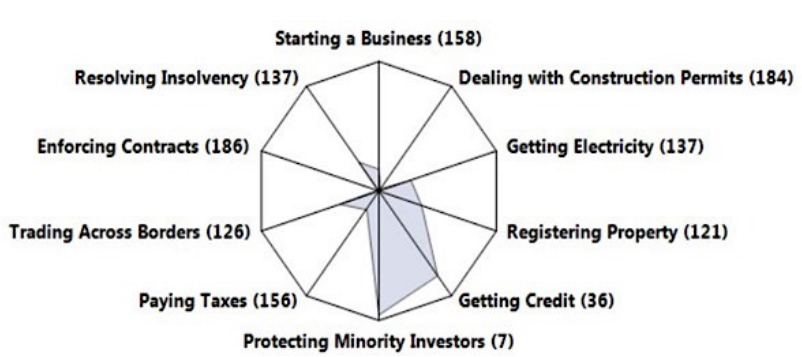

Figure 5: Start up business friendly policies.

friendly policies by governments for the local companies to be able to grow and then enter the global market. To understand this let's have a look at Figure 5.

According to latest World Bank report India has been ranked $142^{\text {nd }}$ out of 189 countries in ease of doing business and has fallen 2 places down in recent years and almost fallen by 10 places since 2011. The most difficult aspect of doing business in India seems to be enforcing contracts. In which, India ranks $186^{\text {th }}$ which is worse than most of the countries in the world. Also, dealing with construction permits is extremely difficult and complex due to high level of corruption in land and construction dealings. Above corruption, the amount of paper work required for construction is very tedious. Not just construction permits but registering a property seems to be quite a task as India ranks $121^{\text {st. }}$. In the most important stage of starting a business, India ranks $158^{\text {th }}$ in the world. This shows that the first step itself is very difficult to take even if you have resources to start a business. While the tax system lacks transparency and there are various taxes in the form for direct taxes, indirect taxes, taxes of central government and taxes of different states, etc. that is why India ranks $156^{\text {th }}$ worldwide in this aspect, which significantly discourages businesses. Getting electricity is an essential and basic part of business to make the business function, even this seems to be difficult along with resolving insolvency.

In both India ranks $137^{\text {th }}$ in the world. India is a big country having several states, each state has different and separate taxes, rules and culture. The connectivity with roads is very poor and trains not 
punctual. This makes it very difficult to carryout trade between the borders. In only 2 sections of the above matrix India does better. Getting credit for business is relatively easy and protection of minority investors is done better. Overall, the market environment of India seems to be not so easy for carrying out a business.

Not only in India but it is the similar situation in most of the emerging nations. Mainly due to similar under-developed market, no transparency in government policies, infrastructure and unskilled labor. Refer to Figure 5 to see how other emerging countries perform in this matrix by World Bank of ease of doing business. Only Mexico appears to be performing relatively better than other BRIC nations. And, India ranks last in all these mentioned nations, which needs to be urgently addresses to promote PM Narendra Modi's 'Make in India' campaign and to produce more MNCs from India.

India seems to be doing relatively well in ease of getting credit and protection of investors but in most of sections India seems to be much difficult nation. This indicates the complexity of carrying out a business in India and in the emerging nations in Figure 6.

\section{Country of origin effect (COE)}

COO or Country of Origin Effect refers to the practice of marketers and consumers associating brands with countries and making buying decisions made on the country of origin of the product. For instance, perfumes made in France are perceived to be superior than perfumed made elsewhere, Cars from Germany, Supercars from Italy, Medicines from USA and UK, Software from USA, etc. While, some countries are also associated negatively with products, for example, Chinese products are perceived as cheaper and low quality products. As, cars from European countries are perceived as the best quality vehicles and are available in all segments, it is difficult for Indian players to change this perception of the buyers. This is very similar in the case of other technological products. Following is the chart (Figure 6) to see the sales of European cars vs. Asian Cars.

To avoid negative impact of COE Titan, A TATA subsidiary for watches and perfumes announced new perfume brand which will bottle the perfume in France to make the product appear as if it is from France and gain the advantage of COE. Skinn, a range of exquisite French fragrances from Titan, is airing an all-French ad film in India. This is for the first time, when a brand is airing an all-French film. Highlighting the French origin of Skinns's range of perfumes, the film was initially aired without subtitles, thus creating intrigue and emphasizing the French connect [23].

\section{Product User Reviews}

According 'Motoring Australia' the overall quality of TATA Xenon is inferior to its competitors. The power and torque is modest and the cabin is not as quiet as its competitors. It is a "work horse" used mainly by farmers and other daily workers in the market where value proposition starts to make sense. There is still doubt about the long-term reliability of the vehicle. The 'CAR ADVICE.com' of Australia stated that the Mahindra pick up $4 \times 4$ is a tough off road but lacks performance on road. They rated the vehicle 9 out of 10 offroad and 5 out of 10 on-road. For Mahindra XUV 500 the caradvice. com stated that the SUV is good enough for a reasonable price tag but its behind its competition in departments like towing capacity, fit and finish and safety which is explained in Figure 7.

For both the Mahindra SUVs XUV 500 and KUV 100 respectively, 'wheels24.com' of South Africa reviewed features of the cars positively but the negative part was the lack of dealer network in Africa which has left the potential buyers unaware of the cars. On the contrary 'ignition.com', 'Cars.co.za' and 'Wheels24.com' reviewed Tata bolt very highly due to its cheaper price and at par features compared to the competition. Crown Publications TV of South Africa created a video of users of TATA Prima Users review, which shows that all the reviewers reviewed the truck very highly with key factors as easy to use, value for money, performance, fuel consumption and reliability.

In the American market, Mahindra competes mainly against John Deere and Kubota in the tractor segment. According the User reviews on 'tractorbynet.com', the Mahindra 2615 tractor gets overall rating of 4.6 by a total of 29 reviews. According 'Mobilewithprices. com' most of the Micromax and Karbonn phones are available at the local shops in Europe but are usually not covered under warranty (Micromax Canvas Mega 2 Plus Price in Europe with Release date, Specs, n.d.).

According to NDTV Gadgets, Micromax Canvas which is in the segment as Xiomi's Mi 4i losses to the later in overall build. The Micromax Canvas 5 comes in at a price of Rs. 11,999, which makes it

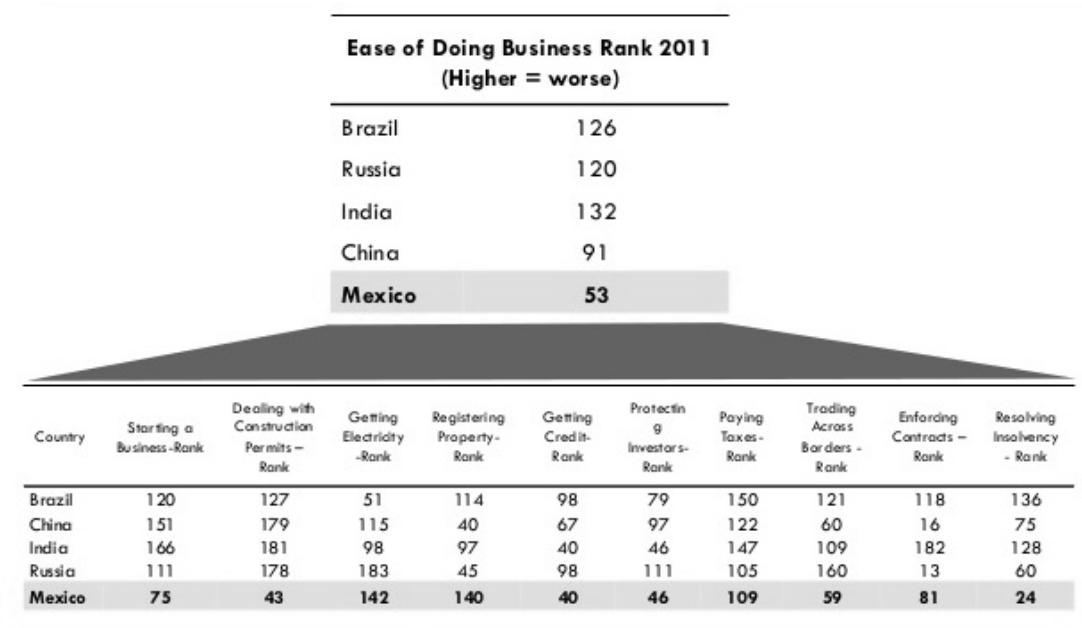

Figure 6: Complexity of carrying out a business in India. 
decent contender in this price bracket especially since the company has promised to bring out an Android

6.0 update in the future. The phone scores big for its display quality, good build, detailed macros in daylight, and good all-round app performance. On the other hand, we weren't too fond of the stock launcher, the battery performance and time it took to charge completely, and the low-light camera performance. Between this phone and the Xiaomi Mi 4i (Review) - which is now available at the same price - we'd have to give our nod to the latter here as it offers better aesthetics and battery life.

\section{Methodology}

The primary data collection for this paper is done with the combination of interviews. Two interviews were arranged for this paper. The interviews were arranged to collect the data from the company's point of view relating to the strategies adopted by Indian companies in the global market. To study the innovation strategies of Indian companies in global market, it is very important to know the different mechanisms used by the company to source knowledge in different markets, patterns of modes of entry, unique internationalization strategies and what hinders a company's aspiration to go international. Therefore, it was necessary to carefully select two companies for collecting primary data. One company with successful global operations and one company which is very

\section{Worldwide car sales, $\mathrm{m}$}

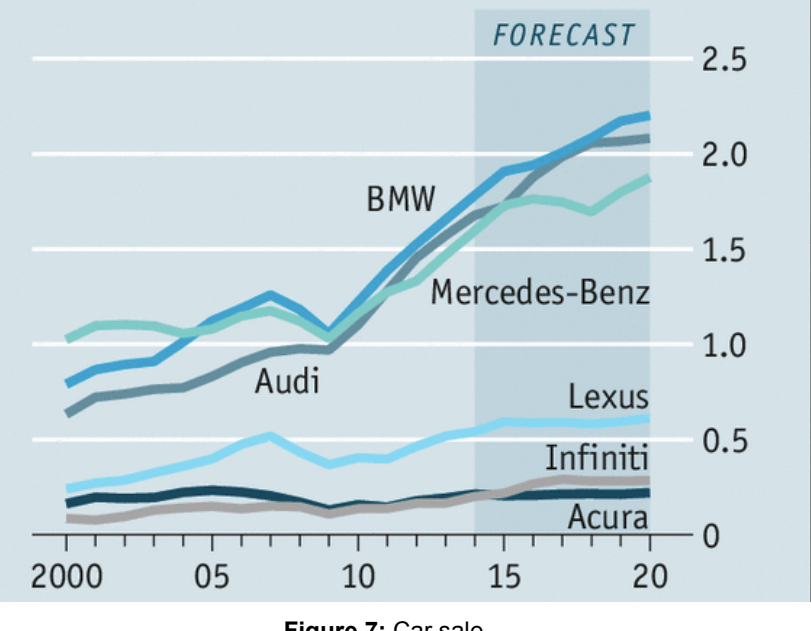

Figure 7: Car sale. successful in domestic market and has potential to go international and is on the verge of going global. Such selection of companies for primary data will provide the paper data which is very vital to understand international innovation strategies of Indian firms. Selection of two similar companies would have provided very similar data thus, selecting two different companies will provide the project how Indian companies operate successfully in International market. As well as, the challenges they face while they are going global. Thus, two separate interviews were conducted to get the data. One interview was arranged with DGM (indirect tax) Mr. Mahadeo Burande of Thermax. D Ltd. Which is an energy and environment engineering company based in India and Britain. The company manufactures boilers, vapour absorption machines, water and waste solutions and installs captive power projects. As to understand what hinders aspirations of the companies to enter international market which have potential to compete in the foreign markets.

The second interview was arranged with the COO Mr. Ketan Ganu of Netsurf Communications Pvt. Ltd. Which is an Indian FMCG based in Pune with very limited international exposure despite of its potential to go international. The company has recently got into JVs with South Korean, US and Sri Lankan companies for their international start. The company manufacture 49 herbal and natural products across 4 categories of health care, personal care, agriculture and home care. The company also offers online shopping of its products through their website and mobile application.

Following is the reasoning table (Table 1) for selection of these companies being chosen for this research paper.

While Thermax was chosen to understand innovation strategies by successful Indian firms in global markets. Netsurf was chosen to understand challenges faced by successful Indian companies while going global at the current period. The data generated from these two interviews will fill the gap of the innovation strategies used by the Indian firms internationalize.

DGM (indirect taxation) of Thermax D Ltd. was contacted and asked for an interview for this paper through personal contacts and the interview was arranged on $22^{\text {nd }}$ February 2017 at 8:52 pm at his residence in Pune. The interview was conducted without much brainstorming to avoid biases in the results. However, the idea of questions which were going to be asked was given prior the meeting over the phone. There was also a brief casual talk regarding the company's global operations prior to the interview, which was also very informative for the paper. The findings of that talk are also discussed in the results and conclusion part of the paper. The complete interview was recorded on the smartphone for further analysis and

\section{Thermax. D Ltd.}

International Company with operations in 72 countries.

Successful in international markets with around $\$ 225 \mathrm{mn}$ exports and $\$ 820$ $\mathrm{mn}$ revenue in 2016 worldwide.

\section{Netsurf Communication Pvt. Ltd}

Indian FMCG company with 49 FMCG products across 4 categories.

Unique business model of direct selling and e-commerce.

Cumulative revenue of around $\$ 106 \mathrm{mn}$.

Headquartered in Pune, India and other major offices in Britain, US, Brazil and China.

Successful international acquisitions to enter More than 2 million domestic customers. International markets. For example, Danstroker A/S to enter Europe and its German subsidiary Omnical Kessel for Euro $29.5 \mathrm{mn}$. Successful collaboration with foreign companies like Sanyo of Japan and Babcock \& Wilcox of USA.
0.8 Million direct sellers in 22 states of India.

Hired US based Launch Smart to enter in US in near future.

Applied for FDA certification for their health care products.

JVs with south Korean, US and Sri Lankan companies for their international start.

Table 1: Difference between the companies chosen for this research purpose. 
to not lose any important data. Throughout the interview there was no interference made to get as much information as possible. No editing was performed on the audio recording to avoid data loss. The questions for the interview were framed in such a way to get all the required data within the time allotted by Mr. Burande. To finish the interview in allotted time and to get the information required two questions were asked, which were drafted a day before the interview to make sure that the questions asked will get required information. Following are the two questions which were asked with the reasoning of why these questions were selected for the interview.

The first question was "I want to ask you about your company's global operations, especially how do you source knowledge about new markets while entering into them?" This question was deliberately framed in a bit generalized manner and not too specific on a specific topic to get as much data as possible in the limited time while not getting completely dragged away from the topic. The question was mainly framed to understand Thermax's strategies of sourcing knowledge by different mechanisms in different markets.

The second question was "So is there any pattern of strategies the company follow?" This question was more specific to understand 'is there really a pattern of market selection by Indian firms' as it appears to be so and the intention was also to get what procedure do Thermax follow to enter into an existing international market or in the new market. The question was also open to other strategies that the company adopts to and how. Here the pattern of strategies is related more to the internationalization of the company which was earlier briefed to Mr. Burande over the phone.

The questions asked got enough information which was required for this paper. After the interview, again there was an informal chat in which information about the vital foreign markets of the company were discussed. The transcript of the same is attached in the Appendix too. The interview was also recorded to make a detailed code book of the findings for better understanding. The analysis of the same is in the next heading 'Data Findings' of the paper. The interview was conducted in English language to avoid translation error and loss of data while the transcript process.

The second interview was conducted with Mr. Ketan at Netsurf's headquarters in Baner, Pune. He was requested for an interview at a dinner event on $2^{\text {nd }}$ March 2017, which was arranged by the chairman of the company Mr Sujit Jain at the company's Pune office. Access to the event was obtained by requesting a distributor of the company. At the dinner, he was given an idea about the nature of the interview and the purpose of the same. He agreed for the interview and it was scheduled on $4^{\text {th }}$ March 2017 at 3:30 pm. While giving him the brief introduction of this paper and the information I needed from him, the questions for the interview were not revealed completely to avoid biases in the actual interview and to get spontaneous responses for more reliable data. On $3^{\text {rd }}$ March, the interview was again confirmed on a social media platform with intention to remind him of the interview. On $4^{\text {th }}$ March prior to the interview Mr. Ketan insisted to talk about the FMP and what exact information about the company is needed. After providing him with relevant answers English was chosen as the language of the interview. Reason being the FMP is in English and for the ease in transcription of the interview. This would also reduce the errors while transcription caused by loss of data while translating. The pre - interview talk was proven to be ice breaker as it helped for gaining more data in the interview. He also took a glance at the project proposal of this paper. The interview started at $3: 42 \mathrm{pm}$ and lasted for around 5 minutes. As the data received was less, brainstorming was done while having a casual talk in the native language after the interview. Brainstorming was done by mentioning the interview Chairman of the company Mr. Sujit Jain gave to a newspaper about Netsurf's international plans. This resulted in him agreeing for another quick interview as the topic seemed to interest him. The second interview then was also conducted in English for above mentioned reasons. The second interview gave the paper more detailed data about the company's international strategies. Both the interviews were recorded on a smartphone after seeking permission. The recording was stopped only when the interview was finished. No editing was performed on the audio recordings to avoid data loss. Links for both the recordings are attached in the Appendix section of the paper. Three questions were prepared for the interview, focusing on the data required by the paper. First question was 'what are the challenges faced by your company while going international and even by other similar companies from India?' This specific question was framed to get detailed information about the current problems faced by companies like Netsurf while going global. The second question was 'does the country of origin effect affect the product in international market?' This question was constructed because of findings from the secondary data which showed country of origin of the product affects the perceived quality of the product in some extent. The question was asked to get know what netsurf thinks of this effect. And the last question was 'how do you plan to overcome these obstacles?' to get the important data of what strategies the company is going to adopt to address the current obstacles ahead of the company. After the interview was over another interview was conducted after few minutes of brainstorming. The questions for this interview were spontaneous and were not framed earlier to the interview. Though the strategy was to get as much detailed information as possible for the paper. In total four questions were asked and every question except the first very dependent on the answer for the preceding question. The first question of the second interview was directly focused on the company's strategy to enter in the US market. To understand, besides hiring US based firm 'smart launch' what else the company is planning for access to the American market. The second question was about the strategy of setting up new manufacturing facility with context to the sourcing of the raw materials and suppliers. This question was based on the answer received from the first one about the company setting up a new plant in Sikkim, India. Third question was asked whether the perceived quality of a new brand will affect the company's sales in global market. This question also got out the positioning strategy of the company in international market. The fourth and last question was about the company's plans for its competitor company called Patanjali which is also a very successful Ayurvedic and herbal FMCG and giving foreign players run for their money in India. After the second interview was over there was a small casual talk which was also very educating and a quick office tour was arranged. Later, Mr. Ketan shared his contact details for further queries. Both the recordings were heard in a quiet place for not missing out any data. For better analysis of the recorded interview, transcript was prepared for the audio file which is attached in the Appendix.

\section{Data Findings}

\section{Themes}

The data collected from the primary sources (interviews) and secondary sources revealed new themes as well as existing themes. It shows 'M\&A is a way to source knowledge in international market as well as to grow.' Data also indicates that it is the most expensive 
way of doing so and thus, carries risk. But, semi-organic way of acquisitions seems to carry relatively less risk. M\&A not only helps to source knowledge from different markets but also to get direct access to those markets with existing business setup and customer base. The theme 'Alliance is also a viable Mechanism to source knowledge of international market if the firm does not have enough funds to acquire other firms' was discovered in the secondary data and was also found in the interviews conducted. Both the companies interviewed hire consultants/agencies in foreign market to source the knowledge of international market. Getting into an alliance with third party having expertise and knowledge of a specific foreign market helps the company in sourcing knowledge without costing much and it also gets the company access to the market. Having said that, sourcing knowledge through third party leads to lack of reliable knowledge or control over the data, which can result in losses to the company like in the case of M\&M and SsangYong. However, a combination of strategies according to the situation and available resources may prove more beneficial. Interview with the DGM of Thermax also helped getting insight of 'sourcing knowledge through expertise in international market' i.e., using own resources to research and acquire knowledge of a specific market. Self-sourcing the knowledge, as well as hiring third party consultants for the same are the two strategies which are in expensive but these strategies are not so reliable and does not get the company access to the markets.

While the theme 'Companies from India started their initial international operations in similar countries. (Mode of Entry Pattern)' founded in the secondary data was also found in the interview of Thermax official. Entering into similar market requires less expertise as the infrastructure of the market and the demand is somewhat similar than the market which is different economically and culturally. On the other hand, both secondary data and interview of Netsurf's COO indicates that health care companies from India tend to target USA first to go international. This is mainly to gain the FDA certification, once a health care company obtains FDA certification it gets very easy for the company to obtain other certifications required in other countries, making entry into those countries easier. Thus, it cannot be said that most companies initially target similar markets to India, instead the business environment triggers the selection of target countries.

The data also states that one of the common strategies of Indian firms while going abroad is to 'Modify the existing product or design new product for the international market.' Due to lack of technological advancement in the nation, there are comparatively less innovation and invention disruptive products. Thus, it is easier to reverse engineer the existing products to make them cheaper and effective to compete with the global leaders. For example, Karbonn's strategy to introduce Microsoft mobiles in Russia. M\&M also uses better quality parts and paints and safer vehicle body compared to Indian models while selling their cars in European and Australian markets. This strategy also lets M\&M to earn more on value added feature and cash on the greater purchasing power of customers in those markets. But creating a new product for specific markets helps to get more market share and proves to be profitable in the long run, For example, DRL's new innovative products. 'Selecting different product for different nations.' Helps the companies to avoid the competition in competitive segments and cash on the segment in which the company has more expertise. This strategy is for companies with wider portfolio, but it helps the company to differentiate in each market and satisfy the exact demand of the market. For example, TATA's commercial vehicles in Poland and hatchback and sedans in India and Latin America. M\&M selects products on the market demand of each country, their strategy is to select their wide portfolio of tractors, utility vehicles, aircrafts and boats according to the demand and the need of the market. Please refer to Appendix for detailed list. Cipla's introduction of cheaper HIV/AIDS and inhalers in South Africa and Nicotex in India.

Another strategy adopted by most Indian firms is to 'reverse engineer the existing products' to save time on innovation and money on R\&D. This also helps the Indian companies to roll out new products with very less time and with the help of cheaper resources, the companies are successful in keeping the cost of products much lesser than the competition. This turns out to be very profitable in the short term to the Indian companies like Cipla, Micromax, Karbonn, etc. The drawbacks of this strategy found in the paper are that due to lack of innovation and expertise, reverse engineered products are inferior in quality to the original ones. As well as, these products do not get the company Intellectual Property Rights (IPRs).

For creating a global image of the brand to succeed in international market and to fade away the COE, common strategy of many Indian firms is of 'Hiring global stars as brand ambassadors to give the brand global image'. This strategy is relatively cheaper as only one ambassador is required globally. For example, Tata association with Lionel Messi. But, the most used strategy is of 'Hiring local stars as brand ambassadors for specific countries. This strategy focuses on separate markets and does not standardize the marketing campaign. Most companies from India follow this strategy to make the product more appealing to local markets, according their cultural tastes. This gives the company an identity of being 'internationally local'. For example, M\&M's strategy of hiring different stars in different market. 'providing the vendors/ suppliers with economies of scale, while procuring raw material. Helps in reducing the cost of production' Cutting down too many suppliers to few or appointed dedicated suppliers results in providing economies of scale to suppliers/ vendors. This in return results in reduction in the cost of procurement of raw materials, keeping the cost of production low. While other new themes which were derived from the interviews are as follows.

- Selling Indian culture (Yoga, Ayurveda, Herbal) in international market (Netsurf): This strategy by netsurf is to gain from the $\mathrm{COE}$ and to enter in a niche market of Ayurvedic and Herbal products segment. The strategy is also adopted to cash on the ongoing trend of Yoga and Ayurved in global market.

- Setting up R\&D according to government regulations (Netsurf): This strategy is to use government regulations as company's guidelines for operations. So, as to get the certifications from the government regulatory bodies efficiently.

- Manufacturing exclusive products for the customers by understanding their needs (Thermax): This strategy by Thermax is only suits to certain industries but this strategy is followed by the company to produce the product exactly according to customer needs, resulting in higher customer satisfaction.

- Different regulations of different countries are a big challenge for Indian companies going abroad (Netsurf): This theme was derived from the interview which stated, that the biggest challenge is to obtain certifications of different regulatory bodies of different countries. While, in the paper 
we also saw that Cipla has strategic tie up with DMFs and ANDAs to get certifications from the regulatory bodies.

\section{Challenges}

Certificates and regulations: From the primary data, it is observed that for a health care and agriculture care company it is the biggest challenge to obtain the different and complex certifications from different regulatory bodies of different nations. Without which it is impossible to enter that market. For example, FDA approval in the US, HALAL certification in Muslim countries, etc. Besides certification, regulatory rules of the nation also affect the company's international operations. For example, USA's regulations for pharmaceutical companies, Indian government's policy to make smartphone companies to make products in India, etc.

Country of origin effect: Secondary data and interview shows that there is COE on the products. Netsurf's COO states that the perceived quality of the Indian products or any other products depends on what price, what level of quality is provided. I.e., he meant, value for money proposition has greater impact than price premium products. According to him, their products are not affected as India is famous for herbal and ayurvedic products. In other words, he accepts that their products have advantage of country of origin effect. He also states that promoting India as a culture or offering products based on the culture of India, will be beneficial for the company in foreign markets as the COE will be used as an advantage. The collected data also suggests that the cars from European nations are preferred over Asian cars.

\section{Conclusion}

\section{Innovation strategies}

Mode of entry strategies and knowledge sourcing strategies: The research suggests that every industry has a different strategy to enter and operate in global markets. The companies like Mahindra, TATA Motors and Thermax adopted more of a 'waterfall strategy' than 'Shower Strategy' to go global. They internationalized from starting with similar markets to India and then trying to propel their global run on acquired expertise and capital. For example, Tata's acquisition of Jaguar and Land Rover, Mahindra's alliance with Peugeot Citroen, SsangYong and Saab and Thermax's strategy of carrying out own surveys in similar markets and appoint third party consultants for markets which are not same as India Cipla, DRL and Netsurf all three targeted USA first. The reason being to get FDA approvals for their products. Once, the health care or pharma companies gets certification from FDA it becomes easy for the companies to export their products to almost every nation. However, to source knowledge DRL uses aggressive inorganic strategy in which they heavily exported to less regulated markets to get easy access to FDA certification, Cipla uses Semi-inorganic strategy and Netsurf uses overseas consultants. Karbonn and Micromax both have resorted to shower strategy while going international. Both the companies entered the Russia, Europe, Middle-East and Indian neighboring countries while going global. While to fund the internalization, Karbonn sold off its $20 \%$ stake and Micromax got into IPO.

From the data analysis: TATA's strategy of acquiring a well-established international brand was more successful than Mahindra's strategy of buying stake in an international brand which is not well established.

- CIPLA's semi-organic strategy seems to be more successful than DRL's aggressive strategy, as DRL has faced some major losses due to aggressive acquiring of firms.

- From above 2 points we can say that careful acquiring or semi-organic growth strategy is the best strategy to source knowledge while going international.

- This paper suggests that instead of cultural similarities or similar markets, needs of the market trigger the mode of entry of an Indian MNC. And thus, it states there is no certain pattern of mode of entry used by Indian firms. The pattern depends upon the nature of the industry and the nature of the products.

Product selection strategies: The paper signifies that every company has different strategy of selecting a specific product for a specific country. For example, Tata focuses on Light Truck Segment in Ukraine, Hatchbacks in India and Latin-America and Pickup trucks in Australia. While, M\&M focuses on Tractors in USA, SUVs in Europe and Africa, Pick-up Trucks, Tractors and SUVs in Australia. Tata failed to provide a SUV in Australian market which prefers 7 seater SUVS. M\&M customized e2o for UK market and priced it almost double to what it costs in India.

Thermax adopts to customization of their products according to customers' need. Netsurf has selected their Ayurvedic and herbal health care products for USA and Bio Agricultural products for Indian neighboring countries. Cipla focuses on cheap HIV/AIDS medications for Africa and DRL focuses on inhalers for American and European markets. Karbonn is focusing on Microsoft OS based mobiles for Russia and on the other hand Micromax does not seem to have any strategy as such.

From the data analysis

- Indian firms seem to provide cheaper alternatives for existing products in a market.

- Mahindra's strategy of introducing SUVs in Australia seems fine but they did not do well as they neglected the local demand of 'SUV's with towing capacity' but on the contrary Tata did not even introduce any of their SUV in the Australian market.

- Companies should adopt little customization strategy according to each market, to satisfy the existing demand in a specific market. For example, e2o by M\&M to cash on the demand by customizing vehicle according to the needs of UK market to gain more profits.

Technological innovation strategies: Talking about the technological innovation strategies of the above companies, TATA used expertise and financial capabilities to produce world's cheapest car TATA Nano and by technology acquired by the acquisition of JLR they recently built a semi-sports car called TAMO Racemo. Mahindra on the other hand, does not seem to have done any disruptive technological innovation in their cars other than few engine upgradations. Thermax has a policy of innovating a product according to every customer's need. Cipla has adopted reverse engineering to save cost and time and to gain over the competition quickly. While, DRL is more into inventions of newer and more effective medications for profits in longer term. Micromax is working on cloud storage and widening their product portfolio. Karbonn's strategy is to introduce Microsoft based smartphones in Russia and to follow Micromax's strategy of widening the portfolio. 
- According to the reviews, both TATA and M\&M vehicles lag in the safety features of their vehicles.

- $\quad$ TATA at-least gained some publicity due to announcing world's cheapest car as well as one of the world's cheapest sports car. But, this has created a perception of Tata cars being cheap compared to the competition.

- DRL's strategy of innovation instead of reverse engineering seem to be more successful.

- Micromax's strategy of widening the portfolio have benefitted it in the domestic market.

- Innovating a product according to every customer's need like Thermax does may not be possible for some industries.

Marketing strategies: Tata's marketing plan of hiring Lionel Messi to give the brand its global image was to change its perception of being Indian market focused company, it did to some extent but the wrong name selection 'zika' and cheaper cars has created their image of being a cheaper car makers. Mahindra had a different plan of hiring local stars as brand ambassador for their cars e.g. Matthew Hayden for Australia and started a campaign "live young, live free" on which all their cars were based. The strategy of Mahindra seems to have been successful as reviewers find M\&M vehicles 'work horses' and have associated their cars with toughness and off-roading vehicles. Micromax had a similar strategy of hiring Hugh Jackman for reducing the country of origin effect but later they changed it by hiring local comedian Kapil Sharma for the Indian market.

The signing of Hugh Jackman proved beneficial for the brand in international market but not for the local market. Karbonn focused on the roughness and durability of their smartphones, has not reached the customers as it should have. Titan's plan to bottle its perfume brand Skinn in France to give the brand an image of being French brand and gain from the COE. Netsurf has a marketing plan of promoting the Ayurvedic and Yogic culture to help create a market for their products which are ayurvedic in nature. Cipla and DRL are major players in generic medicines but according to the findings in the report one out of four American customers doubt the safety and effectiveness of the generic medicines as they are extremely cheaper to the alternative branded medicines. This means their marketing plan is not focusing on addressing the customer's doubts over the quality of the medicines.

- Strategy of hiring a global star as brand ambassador helps in fading the effect of country of origin of the company.

- Local stars tend to appeal more to the local markets than the global stars which the local market does not follow.

- Promoting the culture behind the product helps the product get positive effect of the country of origin e.g. promoting Indian culture to market ayurvedic health care products.

- Assembling the specific product in the country which is famous for manufacturing such product not only helps the company gain from $\mathrm{COE}$, but also is cheaper than manufacturing in that country.

- DRL and Cipla are failing in addressing core issue of educating their end customers about their products.

- M\&M's marketing plan of showcasing their cars as tough and rugged has given them an edge in customer's perceived quality compared to Tata. But both are failing in international market to their competition because they are not able to reward the customers with brand value.

- Karbonn's strategy of showcasing their phones strong is not as successful because the customers feel the design of the product is not at par to the competition.

- Pharmaceutical companies which manufacture generic medicines are not educating enough their end users about the safety and effectiveness of these medicines over branded medicines.

Suppliers and manufacturing strategies: TATA and M\&M's strategy to provide their suppliers with economies of scale and scope with wide product portfolio and producing their vehicles mostly in India has helped them to reduce cost of production due to cheaper raw material and labor. M\&M's failure in US due to not complying with their dealers in the case of 'Foray' has adversely affected their image in the US. While Micromax and Karbonn currently manufacturing in China are planning to manufacture and procure raw material locally due to government policies. Pharma industry is the most affected by the government policies and certifications, Cipla and DRL's example of API procurement ban and Netsurf's challenge of enormous certifications and registrations are few of them. Netsurf strategy of procuring raw material from Sikkim and setting up a plant right next to their suppliers have given them more scope to reduce cost of production by reducing transport cost and loss of raw materials. The companies like Karbonn and Micromax, are poorly rated by the reviewers from Europe in the department of ease of availability in their countries.

- Having certified and less suppliers helps in economies of scale which then helps in reduction in cost of production.

- Most Indian MNC's lack in efficient supply of their products to their end global customers due to inefficient supply chain. Also, resulting in poor after sales services.

- Manufacturing in countries with cheaper labor cost has helped Indian companies to keep their products' prices low.

- Government policies have major impact on MNC's global operations.

Failed strategies: Over ambitious Nano project of Tata which failed due to lack of safety and wrong marketing strategy projecting it as the world's cheapest car, failed the project as the buyers related the car with extremely low quality and cheap which affected company's financials and brand value. Secondly, company's wrong marketing campaign of naming their hatchback 'Zica' also proved to be disastrous. M\&M's failure in supplier's strategy in case of 'Foray' and no innovation in technological department cause underperformance of the company compared to its counterparts. DRL's aggressive acquisition strategy lead to wrong acquisitions resulting in heavy financial blows to the company. DRL's delay in launch of 'Nexium' is also a classic example of inefficiency in executing a plan, resulting in giving away the business to the competition. Micromax and Karbonn both failed in disruptive technological innovation, resulting in having no brand value.

- Automobile companies and smartphone companies in India must invest in R\&D to advance in the field of technology which may solve most of the above issues. 
Citation: Sugre H (2018) Innovation through Internationalization: A Case Study Analysis of Indian Firms. J Glob Econ 5: 276. doi: 10.4172/23754389.1000276

Page 14 of 15

- MNCs from India should set up an efficient dealership network in international market by carefully selecting the dealers on basis of after sale service to gain loyal customers in global markets.

- MNCs should carefully name their products and brands while considering the mean and interpretation of the names in different countries, cultures and languages.

\section{Lack of disruptive innovations}

According to this paper, Indian MNC's are catching up the global players in their own pace but still they are not seen at par with the global competition due lack of quality and no disruptive innovation in the field of technology. For example, there are no pioneer companies like Google, Facebook, Apple, Coca-Cola, Gillette, etc. from India. Indian brands mostly compete on the price proposition rather than quality and thus miss out on the loyal customer base. The reasons for this are that the cheaper labor is not as skilled as the labor from more developed nations. The stronger and positive points of Indian MNCs are their capability of reverse engineering and to come up with a cheaper alternative for a product. The other strong point is huge domestic market, the MNCs from India compared to other MNCs are less affected by losses in international market because the domestic market is huge and growing. Other strong point is of availability of natural resources and cheap labor with young population. India is blessed with abundant natural resources which help Indian MNCs, especially the health care industry to procure good quality cheaper raw material. Not just India but most of the companies from emerging nation lack disruptive innovation as, they are more into reverse engineering.

\section{Under-developed market is affecting the final products}

Indian domestic market is relatively under developed in terms of infrastructure, government transparency, tax system and corruption free bureaucracy. The connectivity is relatively poor compared to the size of the nation. Altogether creates enormous challenges in-front of the companies willing to go abroad or even existing companies to solely focus on their international aspirations. Most of the emerging nations are difficult to do business in, due to similar reasons. This underdeveloped market restricts innovation in the companies. Which finally results in creating the image of companies from emerging nations to be inferior to those from developed countries. As, the companies from developed countries appear to be more innovative and companies from emerging nations appear to provide cheaper alternative to those innovations.

\section{Answering the research questions}

Alliance with foreign companies to gain expertise (knowledge) of specific market:

- $\quad$ Sharing Risk

- Acquire Skills and Knowledge

- Inexpensive

- Lack of control over the knowledge

- Sourcing Knowledge through self-expertise in similar markets:

- Own Market Research

- Efficient for Similar Markets

- Acquire Market Data
- Inexpensive

- Reliable Data

- Outsourcing the job of acquiring knowledge in countries with different markets:

- Hiring Agencies

- Inexpensive than Acquiring

- Efficient for Different Markets

- Less Reliable Data.

\section{Limitations}

The firms mentioned in the paper TATA, M\&M, Cipla, DRL, Micromax and Karbonn being too big it was not possible to set up an interview with concerned official for primary data. With the help of my tutor Mr. Jacob Jojo data related to the firms from emerging economies was gathered along with the secondary data collected from documentaries, news articles, reviews, scholarly articles and web pages. Also, video interviews given by top management of above mentioned firms were closely studied to compensate for the relatively less primary data. Due to limited resources, could not personally travel to countries where these firms operate to collect the primary data. Due to lack of quantitative data, the findings could not be quantified.

\section{References}

1. Rao A, Kadam K (2016) Firstpost. Retrieved October 18, 2016.

2. Duysters G, Jacob J, Lemmens C, Jintian Y (2009) Internationalization and technological catching up of emerging multinationals: a comparitive case study of China's Haier Group. Industrial and Corporate Change 18: 325-349.

3. Tewari S (2016) Retrieved February 20, 2017.

4. Arun SVK (2016) Retrieved February 20, 2017.

5. Jauhari U (2015) rediff. Retrieved February 15, 2017.

6. Balkrishnan R (2015) live mint. Retrieved March 20, 2017.

7. Balakrishanan R (2014) Business Standard. Retrieved October 19, 20156.

8. Mahindra (2012) Mahindra Rise. Retrieved February 10, 2017.

9. Philip L (2014) The Economics Times. Retrieved October 19, 2016.

10. Baggonkar S (2015) Five years on, M\&M awaits Ssangyong turnaround. Retrieved February 20, 2017.

11. Law A (2014) Business Line. Retrieved October 20, 2016.

12. Bicheno S (2016) Retrieved October 20, 2016.

13. ANI (2015) The Financial Express. Retrieved February 15, 2017.

14. Srivastava S (2016) Forbes India. Retrieved February 02, 2017.

15. Rangaswami (2013) Tech First Post. Retrieved February 20, 2017.

16. Chauhan CP (2014) Economic Times. Retrieved March 24, 2017.

17. Prasenjith $P$ (2016) Hindustan times. Retrieved March 20, 2017.

18. Reuters (2017) Business Standard. Retrieved February 15, 2017.

19. Dutta A (2016) Business Standard. Retrieved March 20, 2017.

20. Bhatt S (2012) Campaign India. Retrieved February 12, 2017.

21. Phadnis A (2015) Business standard. Retrieved March 07, 201.

22. Kurczewski N (2009) Wheels. Retrieved February 26, 2017.

23. Hislop M (2017) designboom. Retrieved April 20, 201.

24. Mahalakshmi B (2014) The Financial Express. Retrieved February 15, 2017 
Citation: Sugre H (2018) Innovation through Internationalization: A Case Study Analysis of Indian Firms. J Glob Econ 5: 276. doi: 10.4172/23754389.1000276

25. Pai V (2016) Retrieved February 20, 2017.

26. Basheer S (2014) Indian Express. Retrieved February 15, 2017.

27. Reddy BD (2016) Business Standard. Retrieved February 15, 2017.

28. Mohile SS (2014) live mint. Retrieved 01 12, 2017.

29. Joshi A (2015) Retrieved February 20, 2017.

30. Khan D (2015) The Economic Times. Retrieved February 20, 2017.

31. Joshi S (2016) Mashable. Retrieved February 15, 2017.
32. Berkowitz J (2012) Car and Driver. Retrieved February 15, 2017.

33. Mishra AK (2012) Forbes India. Retrieved February 15, 2017

34. Banerjee P (n.d.) Mckinsey. Retrieved April 26, 2017

35. Mahajan A (2016) Trak.in. Retrieved April 02, 2017.

36. Parker S (2016) Wheels 24. Retrieved March 20, 2017.

37. Cerejo R (2015) NDTV Gadgets. Retrieved March 21, 2017. 